\title{
Influence of Current Intensity and Heat Input in MIG-Brazed Joints of DP 600 Thin Zinc Coated Steel Plates
}

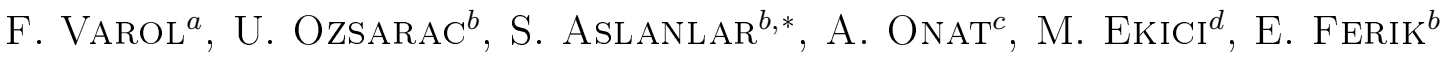 \\ ${ }^{a}$ Vocational School of Karasu, Sakarya University, Sakarya, Turkey \\ ${ }^{b}$ Department of Metallurgical and Materials Engineering, Sakarya University, 54187 Sakarya, Turkey \\ ${ }^{c}$ Marmara University, Technology Faculty, Department of Mechanical Engineering, Istanbul, Turkey \\ ${ }^{d}$ Vocational School of Yalova, Yalova University, Yalova, Turkey
}

\begin{abstract}
In this study, DP 600 (Dual-Phase) steel plates having $1 \mathrm{~mm}$ thickness were joined by copper-based $\mathrm{CuAl} 8$ wire in gas metal arc brazing technique. Specimens were prepared as butt joint. Brazing operations were done with ten different arc voltages and weld currents as 40,45, 50, 55, 60, 65, 70, 75, 80 and 85 A. Tensile strength, bending force, microstructure of brazed materials, and their microhardness distribution throughout joining were determined. In macro and microstructure examinations, stereo optical microscope, scanning electron microscope (SEM) and energy dispersive spectroscopy were used. This study investigated the effects of current intensity on microstructure and microhardness distribution of transition zone between DP 600 steel and MIG-brazed joint. The tensile strength and bending resistance increase with increasing current intensity.
\end{abstract}

DOI: $10.12693 /$ APhysPolA.127.968

PACS: $81.20 . \mathrm{Vj}, 81.70 . \mathrm{Bt}, 81.05 . \mathrm{Bx}$

\section{Introduction}

In recent years great amount of attention has been focused on reducing the weight of vehicles to reduce fuel consumption and exhaust gas emission. Therefore, using high strength materials, which provide higher strength for automobile body parts, has rapidly increased in the sheet metal industry [1].

Dual phase steels are among the most important advanced high strength steel (AHSS) products recently developed for the automotive industry. These are very interesting for light weight constructions because it combines a high ultimate strength with a high fracture strain [2]. The dual phase DP 600 steel, which is among the steels developed within the scope of measures to provide fuel saving, has become a product widely used in automotive industry $[3,4]$. The DP 600 steel enables both a reduction in vehicle weight, an increase in strength for those carrying greater loads, and provides thinner application thickness [5]. The DP 600 steel was reported as being used in automobile applications, in parts such as seat flange, wheel, wheel webs, light weighted longitudinal rails, shock towers, and fasteners $[4,5]$. The car assembly industries have recently been using zinc-coated carbon steel sheets in passenger car bodies because they combine good mechanical properties, good corrosion resistance and low purchase cost of this material [6]. Galvanized DP steel sheets are widely used in construction with corrosion resistance and especially in the automotive industry [7-10]. In this paper, MIG-brazing of galvanized steel sheets were studied by using copper based filler and

${ }^{*}$ corresponding author; e-mail: aslanlar@sakarya.edu.tr it was found that the joint strength is higher than that of the base materials $[9,10]$.

\section{Experimental studies}

\subsection{Materials}

A zinc coated DP 600 dual phase automotive steel which was mainly ferritic with a fraction of hard phases of martensite was used in this study. In the tests the steel plates were $1 \mathrm{~mm}$ thickness, with $7.5 \mu \mathrm{m}$ zinc coating. DP 600 steel plates were cut $200 \times 200 \times 1 \mathrm{~mm}$. The sheets were positioned end to end to allow a gap between them $0.5 \mathrm{~mm}$, and were subjected to joining by MIG-brazing process. The copper-based filler metal was a solid wire with a diameter of $1 \mathrm{~mm}$ and classified as AWS ERCuAl8. Argon was used as the shielding gas at a flow rate of 12 liter $/ \mathrm{min}$.

\subsection{Methods and procedure}

MIG-brazing operations were carried out in a current control MIG-brazing machine having 300 A capacities. The current values for brazing operation were determined as $40,45,50,55,60,65,70,75,80$ and $85 \mathrm{~A}$ in butt joint form. The surface of the samples was cleaned by acetone before MIG-brazing operation. Ten sets of joining parameters with different heat inputs were selected, as given in Table I. The heat input, $H I_{\text {linear }}$ and $H I_{\text {normalized }}$ were calculated by using the Eq. 1 and 2 respectively;

$$
\begin{aligned}
& H I_{\text {linear }}=\frac{(60 \times U I) \eta}{V}, \\
& H I_{\text {normalized }}=\frac{H I_{\text {linear }}}{e},
\end{aligned}
$$

where $\eta_{M I G}=0.7$ is the arc efficiency factor, $e$ : thickness $(\mathrm{mm}), U$ and $I$ are the mean values for the arc voltage, 
respectively for the current intensity and $V(\mathrm{~cm} / \mathrm{min})$ is the brazing speed [11]. MIG-brazing parameters such as current intensity, voltage, and wire feed speed were presented in Table I. All brazing operations were performed by 12 liter/min shielding gas flow rate, $24 \mathrm{~cm} / \mathrm{min}$ brazing travel speed and $0.5 \mathrm{~mm}$ brazing gap.

MIG-brazing parameters TABLE I

\begin{tabular}{c|c|c}
\hline $\begin{array}{c}\text { Current } \\
\text { Intensity } \\
(\mathrm{A})\end{array}$ & $\begin{array}{c}\text { Wire Feed } \\
\text { Speed } \\
(\mathrm{m} / \mathrm{min})\end{array}$ & $\begin{array}{c}\text { Voltage } \\
(\mathrm{V})\end{array}$ \\
\hline 40 & 2.0 & 11.6 \\
\hline 45 & 2.2 & 11.7 \\
\hline 50 & 2.5 & 11.8 \\
\hline 55 & 2.8 & 12.0 \\
\hline 60 & 3.1 & 12.1 \\
\hline 65 & 3.4 & 12.3 \\
\hline 70 & 3.7 & 12.4 \\
\hline 75 & 4.0 & 12.6 \\
\hline 80 & 4.1 & 12.7 \\
\hline 85 & 4.3 & 12.8 \\
\hline
\end{tabular}

\section{Experimental results and discussion}

\subsection{Tensile tests}

To measure the standard joint strength, the tensile testing was conducted at first. The experiments showed that most of the tensile test specimens fractured from the base metal. $60,65,70,75,80$ and 85 A currents showed that the strength of the joint zone was higher than that of the base metal zone and the $\mathrm{CuAl} 8$ filler zone. It was obvious that the joint zone was strengthened. In 40, 45, $50 \mathrm{~A}$, insufficient wetting occurred as a result of low heat input and excessive spatter took place in the filler metal. That situation in the filler metal resulted in disorder in the brazed geometry. $55 \mathrm{~A}$ current intensity came about a critical point in decreasing spatter in the filler metal and increasing maximum tensile strength. The strength values are seen in Table II, it was observed that strength increased with the increase in current intensity, which were parallel with heat input and wetting. However, unstable increases were detected in strength values above 65 A. Moreover, DP 600 steel sheet, in $1 \mathrm{~mm}$ thickness, was punctured above $85 \mathrm{~A}$. After the bending test, no fracture was observed in the joint zone. It was seen that bending force increased with increasing heat input depending on current intensity. The highest tensile strength value was observed as $648 \mathrm{MPa}$ at $80 \mathrm{~A}$ current intensity, while the lowest was $248 \mathrm{MPa}$ at $40 \mathrm{~A}$. Similarly, $624 \mathrm{~N}$ is the highest bending force measured in joints brazed at $85 \mathrm{~N}$, while the lowest was $350 \mathrm{~N}$ for samples brazed at $40 \mathrm{~A}$. Tensile strength, bending force and amount of heat input values increase with increasing current intensity.

\subsection{Microhardness test}

Figure 1 shows the measured microhardness values of the joints for different weld currents. It was seen that
Experimental results for different MIG-

TABLE II brazing currents

\begin{tabular}{c|c|c|c|c}
\hline $\begin{array}{c}\text { Current } \\
\text { intensity } \\
(\mathrm{A})\end{array}$ & $\begin{array}{c}\text { Tensile } \\
\text { strength } \\
(\mathrm{MPa})\end{array}$ & $\begin{array}{c}\text { Bending } \\
\text { force } \\
(\mathrm{N})\end{array}$ & $\begin{array}{c}\text { Heat input } \\
\left(H I_{\text {linear }}\right) \\
(\mathrm{J} / \mathrm{cm})\end{array}$ & $\begin{array}{c}\text { Heat input } \\
\left(H I_{\text {normalized }}\right) \\
(\mathrm{J} / \mathrm{cm} / \mathrm{mm})\end{array}$ \\
\hline 40 & 248 & 350 & 812 & 812 \\
\hline 45 & 452 & 444 & 921 & 921 \\
\hline 50 & 497 & 481 & 1033 & 1033 \\
\hline 55 & 603 & 500 & 1155 & 1155 \\
\hline 60 & 635 & 515 & 1271 & 1271 \\
\hline 65 & 638 & 523 & 1399 & 1399 \\
\hline 70 & 628 & 540 & 1519 & 1519 \\
\hline 75 & 635 & 558 & 1654 & 1654 \\
\hline 80 & 648 & 610 & 1778 & 1778 \\
\hline 85 & 633 & 624 & 1904 & 1904 \\
\hline & & & &
\end{tabular}

microhardness value reached the highest at HAZ and the HAZ's hardness was higher than that of the copper filler and base material. Microhardness value of the joint zone increased with the increase in current intensity. Vickers microhardness measurement points along the specimen from base metal, heat affected zone (HAZ) and to the brazing zone and the measurement results of all specimens were presented in Fig. 1. The hardness of base metal was measured as $180 H V_{0.1}$. This region is far away the brazing zone, so heat input cannot make any
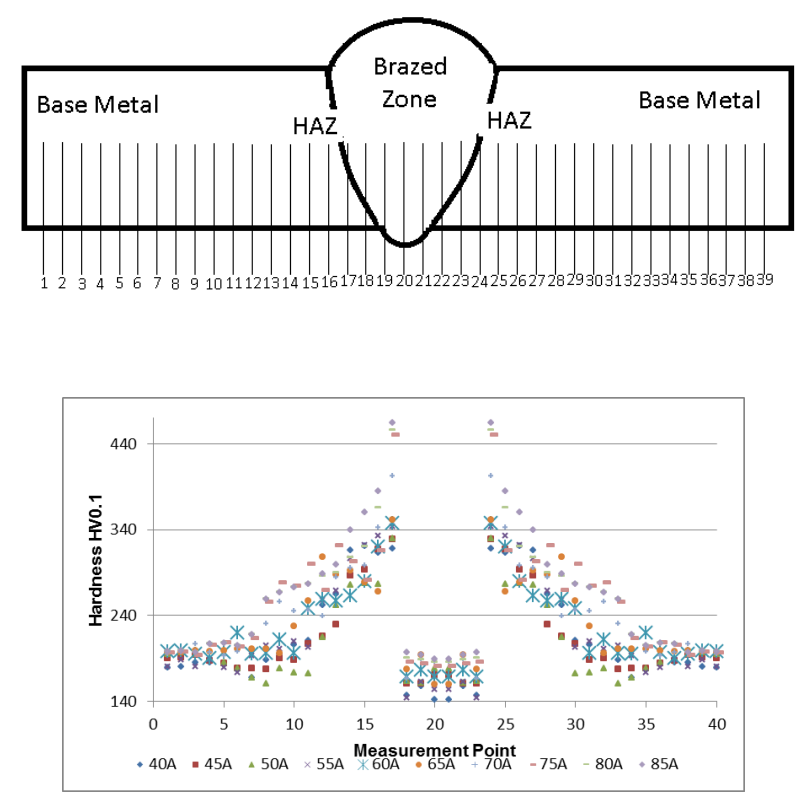

Fig. 1. The points where hardness values were taken from in butt joint.

change in microstructure. Hardness starts to decrease while moving towards to joint zone. In this region grain growth is observed due to excessive heat input to steel. The weakest zone is here named heat affected zone (HAZ) 
in all welding processes. However, in metal inert gas brazing operation, the hardness value was increased up to approximately $400 H V_{0.1}$. The main difference between welding and MIG-brazing is this strength increment in HAZ. The base metal is melted in order to obtain weld pool and consequently melting of filler metal; but in brazing only filler wire is melted and by means of capillary forces it spreads along the joint distance. Grain growth is more restricted with respect to welding process. The hardness sharply decreases to $160 H V_{0.1}$ values in brazing zone (i.e. joint zone) which is lower than initial hardness value.

\subsection{Macro and microstructures}

SEM microstructures of brazed joints for different MIG-brazing currents were shown in Fig. 2. The molten metal wetted the steel better when using 60, 65, 70, 75, 80 and 85 A current intensities, comparing to samples brazed in 40, 45, 50, $55 \mathrm{~A}$ at lower heat input. During the arc brazing process, it was observed that the number of dendrites increased on the surface of the joint zone with the increase of current intensity and these dendrites caused micro iron particles to melt and migrate, and to become distributed throughout the filler metal zone. The dendritic structure of the brazed metal in this study is similar with the studies of Chovet [10], Varol et al. [11] and Akkas et al. [12].

\section{Conclusions}

The effect of current intensity and amount of heat given in MIG-brazing process on mechanical properties of dual phase, ferritic-martensitic steel sheet joints was investigated and the following conclusions were drawn:

- MIG-brazing method provided lower heat input in comparison with other fusion methods. Low heat input resulted in less zinc evaporation from DP 600 galvanized sheet.

- An unstable increase occurred in the strength values in Table II because of excessive heat input in 70 , 75, 80 and 85 A current intensities. Hence, 60-65 A was determined as the most suitable and optimum current intensity range.

- SEM images confirmed that diffusion of iron atoms increased as a result of high heat input with increasing current intensity. The increase of iron diffusion brought about stretching of dendrites like branches. Additionally, increase of dendrites resulted in increase of hardness and strength.

\section{Acknowledgments}

The authors wish to thank to Sakarya University Scientific Research Foundation (Project number: 2010-0506-008) for their support.
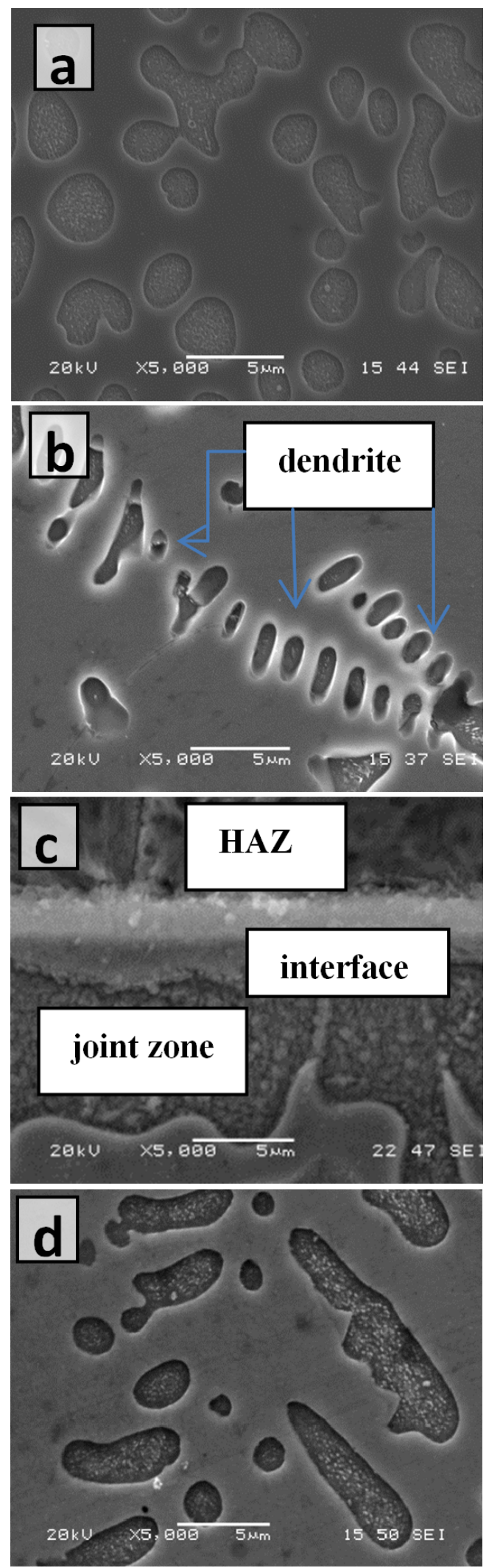

Fig. 2. SEM images for MIG-brazing of DP600 steel with $\mathrm{CuAl} 8$ wire. 


\section{References}

[1] F. Ozturk, S. Toros, S. Kilic, Iron Steel Res. Int. 16(6), 41 (2009).

[2] J.A. Kadkhodapour, S. Butz, R. Ziaei, S. Schmauder, International Journal of Plasticity 27, 1103 (2011).

[3] X.Q. Zhang, G.L. Chen, Y.S. Zhang, Mater. Design 29, 279 (2008).

[4] F. Hayat, Iron Steel Res. Int. 18(9), 70 (2011).

[5] J. Bian, Y. Zhu, X. Liu, Iron Steel Res. Int. 13(3), 47 (2006).

[6] AWS. Welding Processes in: Welding Handbook Vol. 2, 8th ed., AWS, Miami 1991.
[7] A.F. Rangel, L.A. Matlakhova, R. Da, R.P. Paranhos, A.N. Matlakhov, Welding International 20(11), 889 (2006).

[8] R.F. Li, Z.S. Yu, K. Qi, Transactions of Nonferrous Metals Society of China 16, 397 (2006).

[9] Z.S. Yu, Y.Y. Qian, R.F. Li, F.M. Zhou, Materials Science and Technology 10, 1399 (2003).

[10] C. Chovet, S. Guiheux, International Conference Super High Strength Steels, organized by AIM, Roma, 2-4 Nov., (2005).

[11] F. Varol, M. Colak, N. Akkaş, U. Özsaraç, S. Aslanlar, Materialprufung 56(10), 858 (2014).

[12] N. Akkaş, F. Varol, E. Ferik, E.İlhan, U. Özsaraç, S. Aslanlar, Acta Phys Pol A. 125, 473 (2014). 